\title{
Partição ambiental de Potimirim glabra (Kingsley) e Potimirim potimirim (Müller) (Crustacea, Decapoda, Atyidae) no rio Sahy, Mangaratiba, Rio de Janeiro, Brasil
}

\author{
Giovana V. Lima ${ }^{1}$ \\ Lídia M. Y. Oshiro ${ }^{1}$
}

\begin{abstract}
Environmental partition of Potimirim glabra (Kingsley) and Potimirim potimirim (Müller) (Crustacea, Decapoda, Atyidae) in Sahy River, Mangaratiba, Rio de Janeiro, Brazil. This work aims to determinate the spatial distribution of two sympatric freshwater shrimp species, Potimirim glabra (Kingsley, 1878) and Potimirim potimirim (Müller, 1881) in Sahy River, municipality of Mangaratiba. The populations were collected from September, 1997 to February, 1999. The animals were collected monthly by sieving the marginal vegetation, on rocky surface and among litter on river bottom. The animals were sorted sexed. Their carapace length measured and total length measured. A total of 4,889 animals were collected in Sahy River: 3,281 P. glabra and 1,608 P. potimirim. The spatial distribution of $P$. glabra and P. potimirim showed an environmental partition. Potimirim glabra occurred in abundance at the farthest stations from the beach, wilst and $P$. potimirim, at the nearest stations from the sea.

KEY WORDS. Potimirim glabra, Potimirim potimirim, spatial distribution, environmental partition
\end{abstract}

A família Atyidae, registrada apenas para as Américas, está representada por dezenove gêneros (HolTHUIS 1955), destacando-se como importante componente dos sistemas tropicais e subtropicais de água doce, exercendo importante papel na cadeia trófica dos ambientes limnícos (BENZIE 1982).

Segundo RoDRIGUEZ (1980), os Atyidae são camarões predominantemente de água doce, limitando-se a rios com águas claras e correntes rápidas, entre rochas e raízes, onde, eventualmente, são levados para o mar presos às plantas aquáticas. BARROS \& FONTOURA (1996) afirmam que, mesmo que ocorram algumas espécies do gênero em água salobra, não são conhecidas espécies marinhas do gênero Potimirim.

No Brasil, são registradas somente duas espécies de Atyidae: Potimirim glabra (Kingsley, 1878), que se distribui nos Estados do Rio de Janeiro, São Paulo e Santa Catarina, e Potimirim potimirim (Müller, 1881) nos Estados de Pernambuco, Alagoas, Bahia, Rio de Janeiro, São Paulo e Santa Catarina (RAMOs-PORTO \& COElHo 1998; PAIM et al. 1997 e LIMA \& OSHIRO 1999).

Este trabalho tem como objetivo caracterizar a distribuição espacial de duas espécies simpátricas de camarões de água doce, $P$. glabra e $P$. potimirim no Rio Sahy, pois informações sobre a bioecologia destas espécies ainda são escassas.

1) Estação de Biologia Marinha, Universidade Federal Rural do Rio de Janeiro. Rua Sereder, Itacuruçá, 23860-000 Mangaratiba, Rio de Janeiro, Brasil. E-mail: oshiro@ufrrj.br 


\section{MATERIAL \& MÉTODOS}

As coletas foram realizadas no Rio Sahy (22 $56^{\prime}$ 'S e $\left.44^{\circ} 01^{\prime} \mathrm{W}\right)$, litoral sul do Estado do Rio de Janeiro, durante o período de setembro de 1997 a fevereiro de 1999.

Os exemplares foram capturados mensalmente por duas pessoas utilizandose peneiras de $2 \mathrm{~mm}$ de abertura de malha passadas sob a vegetação marginal, laterais rochosos e sob a matéria orgânica em decomposição no leito do rio, durante 15 minutos. O Rio Sahy foi dividido em seis estações de coleta, segundo suas distâncias em relação à foz e declividade do terreno, sendo: as estações I e II, os pontos mais distantes, com aproximadamente $2 \mathrm{~km}$ em relação à foz, apresentando alta declividade, velocidade elevada das águas e ausência de influência da maré; as estações III e IV, os pontos intermediários do rio, apresentando declividade média, velocidade reduzida das águas e ausência de influência da maré; e as estações V e VI, os pontos mais próximos à foz, caracterizados por pequeno declive, reduzida velocidade das águas e constante influência de maré.

Todos os indivíduos capturados foram levados ao laboratório, fixados em formaldeído $10 \%$, triados e conservados em álcool a 70\%. Após a sexagem, cada indivíduo foi separado em diferentes estágios de maturidade sexual. Posteriormente, cada exemplar foi mensurado em relação ao comprimento total e o comprimento do cefalotórax, utilizando-se um paquímetro de $0,1 \mathrm{~mm}$ de precisão.

\section{RESULTADOS E DISCUSSÃO}

Foram coletados 4.889 animais, sendo 3.281 exemplares de $P$. glabra e 1.608 exemplares de $P$. potimirim. Potimirim glabra apresentou 1530 machos, 1517 fêmeas e 234 jovens; enquanto $P$. potimirim apresentou 1.112 machos, 485 fêmeas e 11 jovens.

A distribuição espacial dos diferentes morfotipos de $P$. glabra diferiu da distribuição de $P$. potimirim (Tab. I).

Tabela I. Distribuição dos diferentes estágios de maturidade sexual de Potimirim glabra e $P$. potimirim através das estações de coletas no Rio Sahy, durante o período de setembro de 1997 a fevereiro de 1999.

\begin{tabular}{lcccccc}
\hline Estágios de maturidade sexual & \multicolumn{5}{c}{ Estações de coleta (\%) } \\
\cline { 2 - 7 } & I & II & III & IV & V & VI \\
\cline { 5 - 7 } & & & & & \\
Potimirim glabra & 12,4 & 24,4 & 31,7 & 30,0 & 1,5 & 0 \\
Machos Imaturos & 63,4 & 20,5 & 10,0 & 6,0 & 0,1 & 0 \\
Machos Maturos & 30,6 & 26,8 & 15,5 & 26,0 & 1,1 & 0 \\
Fêmeas Imaturas & 45,5 & 28,5 & 12,2 & 12,8 & 1,0 & 0 \\
Fêmeas & 38,8 & 24,5 & 17,1 & 19,6 & 0 & 0 \\
Fêmeas Ovigeras & 9,4 & 28,0 & 33,8 & 22,0 & 6,8 & 0 \\
Juvenis & & & & & 0 & 0 \\
Potimirim potimirim & 0 & 23,0 & 17,0 & 60,0 & 0 & 0 \\
Machos Imaturos & 1,8 & 7,0 & 33,5 & 57,7 & 0 & 0 \\
Machos Maturos & 6,4 & 24,0 & 30,4 & 39,2 & 0 & 0 \\
Fêmeas Imaturas & 10,3 & 19,7 & 29,2 & 40,0 & 0,8 & 0 \\
Fêmeas & 21,1 & 2,8 & 18,3 & 55,0 & 2,8 & 0 \\
Fêmeas Ovigeras & 0 & 0 & 0 & 0 & 100,0 & 0 \\
Juvenis & & & & & 0 \\
\hline
\end{tabular}


As fêmeas ovígeras e os indivíduos maturos de $P$. glabra, ocorreram preferencialmente, nas estações mais a montante do Rio Sahy; enquanto $P$. potimirim ocorreu ao longo das estações intermediárias. Possivelmente, a distribuição dos indivíduos maturos de $P$. glabra está associada a um ambiente em declive com maior correnteza e maior presença de rochas, enquanto $P$. potimirim está associada a um ambiente com água de menor correnteza, sem rochas, com as margens ricas em vegetação marginal e, ainda, de um leito provido de grande número de substrato com folhiço em decomposição.

De acordo com KREBS \& DAVIES (1996), essa agregação dos parceiros sexuais propicia maiores oportunidades para a poliginia; ficando o sucesso reprodutivo das fêmeas limitado, principalmente, pelo acesso aos recursos alimentares e ao local de procriação; enquanto os machos ficando limitados ao acesso às fêmeas.

Os juvenis de $P$. glabra ocorreram em todos os pontos do Rio Sahy, exceto na estação VI, apresentando uma maior freqüência de indivíduos na estação III. Potimirim potimirim, no entanto, apresentou os juvenis distribuídos somente na estação V. A presença desses indivíduos ao longo dessa estação, demonstra uma necessidade por água salobra durante o seu desenvolvimento; e ainda, a necessidade por maiores nichos de refúgios ao longo da vegetação marginal, com um ambiente lêntico, mais raso e de menor declividade que promova um maior aquecimento das águas resultando, consequentemente, num maior crescimento das espécies. Esse comportamento concorda com RODRIGUEZ (1981), onde menciona que alguns camarões têm necessidade de uma determinada concentração de cloretos durante o seu desenvolvimento larval.

Durante o estudo verificou-se que $P$. glabra e $P$. potimirim não ocorreram na estação VI, onde há maior variação e influência da salinidade. Isso vem demonstrar uma preferência nítida de ambas as espécies por salinidades mais reduzidas, concordando com RODRIGUEZ (1981), que afirma serem esses animais os primeiros decápodos estritamente de água doce, embora ainda mantenham-se nas proximidades da foz dos rios.

Os machos imaturos de $P$. glabra ocorreram em maior freqüência na estação III, enquanto os de $P$. potimirim, ocorreram na estação IV. As fêmeas imaturas de $P$. glabra ocorreram em maior abundância na estação I, enquanto as imaturas de $P$. potimirim ocorreram na estação IV.

Potimirim potimirim e $P$. glabra parecem apresentar uma ampla seleção de habitats ao longo do rio, concordando com os dados obtidos por MARTínEZ-MAYÉN et al. (2000) no Peru, onde verificaram a presença de juvenis de Atya margaritacea (A. Milne-Edwards, 1864), ao longo das margens do rio associados à vegetação semi-submersa, enquanto os adultos ocorriam em áreas com águas de maior correnteza, associados a fundos com substratos rochosos.

A distribuição espacial demonstrou que ambas as espécies ocupam porções distintas no Rio Sahy. Potimirim glabra apresentou maior número de animais na estação I reduzindo sua frequeência com a proximidade da foz. Por outro lado, $P$. potimirim apresentou maior número de animais na estação IV com redução de suas freqüências com a proximidade da nascente (Fig. 1). 


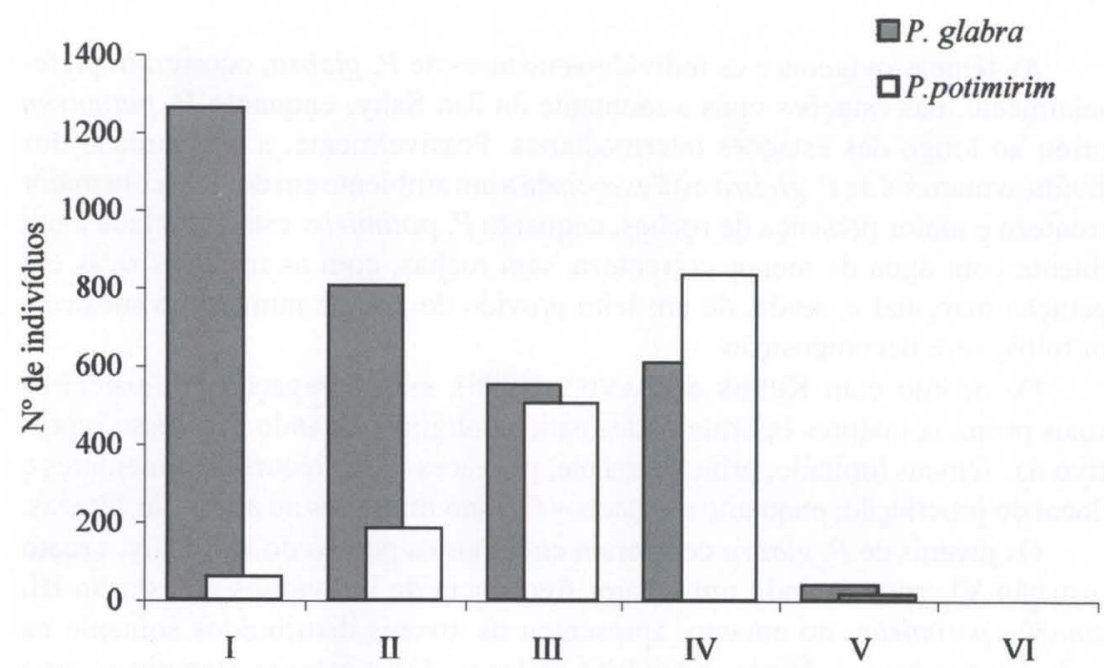

Estações de Coleta

Fig. 1. Partição ambiental de Potimirim glabra e P. potimirim no Rio Sahy, durante o período de setembro de 1997 a fevereiro de 1998.

Essa partição ambiental e distribuição diferenciada deve ocorrer devido ao potencial de tolerância e preferência das espécies.

RAMOS-PORTO \& PALÁCIOS (1981), afirmam que P. potimirim prefere trechos calmos do rio, com fundo arenoso, encontrando-se abrigados sob a vegetação marginal. Potimirim glabra abriga-se, também, na vegetação marginal, mas distribuindo-se em rios com seixos e fluxo hídrico de intensidade moderada a rápida (CHACE \& HobBs 1969).

No Rio Sahy, as duas espécies ocorreram nas mesmas estações de coleta, mas em freqüências antagônicas, demonstrando preferências diferenciadas e partição ambiental, possivelmente por possuírem a mesma valência trófica.

AGRADECIMENTOS. Aos doutores Marcelo Antônio Amaro Pinheiro (UNESP-Jaboticabal) e Lenício Gonçalves (UFRRJ) pelas sugestões durante a defesa da Dissertação apresentada ao Curso de Ciências Ambientais e Florestais, na UFRRJ. À Zootecnista Charlene M. Silveira, ao Sr. Casemiro A. Alves e, ao meu pai, Benedito Albernaz Lima, pelo auxílio nas coletas mensais.

\section{REFERÊNCIAS BIBLIOGRÁFICAS}

Barros, M.P. \& N.F. Fontoura. 1996. Crescimento de Potimirim glabra (Kingsley, 1878) (Crustacea, Decapoda, Atyidae), na Praia da Vigia, Garopaba, Santa Catarina, Brasil. Nauplius, Rio Grande, 4: 11-28.

BEnZIE, J.A.H. 1982. The complete larval development of Caridina maculochi Roux, 1926 (Decapoda, Atyidae) reared in the laboratory. Jour. Crust. Biol., Washington, DC, 2 (4): 493-513.

ChACE JR., F.A. \& H.H. HobBS JR. 1969. The freshwater and terrestrial Decapoda crustaceans of the West Indies special reference to Dominica. Bull. U.S. Nat. Mus., Washington, DC, 292: 1-243. 
Holthuis, L.B. 1955. The recent genera of the caridean and stenopodidean shrimps (Class Crustacea, order Decapoda, supersection Natantia) with keys for their determination. Zool. Verth., Leiden, 26: 1-157.

KREBS, J.R. \& N.B. DAVIES. 1996. Introdução à ecologia comportamental. São Paulo, Ed. Atheneu, 420p.

LimA, G.V. \& L.M.Y. Oshiro, 1999. Aspectos reprodutivos do camarão de água doce Potimirim potimirim (Müller, 1881) (Crustacea, Decapoda, Atyidae) do Rio Sahy, Mangaratiba/RJ. Nauplius, Rio Grande, 7: 65-71.

Martínez-Mayén, M.; R. Román-Contreras; A. Rocha-Ramírez \& S. Chazaro-OlverA. 2000. Relative growth of Atya margaritacea A. Milne-Edwards, 1864 (Decapoda, Atyidae) from the southern pacific coast of Mexico. Crustaceana, Leiden, 73 (3): 524-534.

Paim, J.P.; M.C. Peso-Aguiar; C.R.G. CARqueja; T.C.A. Almeida \& R.C.F. Assis. 1997. Ocorrência de Potimirim potimirim (Müller, 1881) (Crustacea, Decapoda, Atyidae) no Rio Mucuri-Bahia. Nauplius, Rio Grande, 5(2): 147-148.

Ramos-Porto, M \& P.A. CoelHo. 1998. Malacostraca. Eucarida (Alpheoidea excluded), p. 325-350. In: P.S. Young (Ed.). Catalogue of Crustacea of Brazil. Rio de Janeiro, Museu Nacional, Série Livros no. 6, 717p.

Ramos-Porto, M. \& J.A.P. Palácios. 1981. Estudo ecológico do Rio Capibaribe - Mirim, PE. IV. Crustáceos decápodas natantes. Trabr. Oceanogr. Univ. Fed. Pernambuco., Recife, 16: 265-296. Rodriguez, G. 1980. Los crustaceos decapoda de Venezuela. Caracas, Instituto Venezoelano de Investigaciones Científicas, 494p.

- 1981. Decapoda, p. 41-51. In: S.H. HurlberT; G. Rodriguez \& N.D. Santos (Eds). Aquatic Biota of Tropical South America, Part 1: Arthropods. San Diego, San Diego State Univ., 278p.

Recebido em 19.VIII.2002; aceito em 27.XI.2002. 